\title{
PERINATAL AND MATERNAL OUTCOME IN PREMATURE RUPTURE OF MEMBRANES
}

\author{
Mercy Rodrigo Rexy Rodrigo ${ }^{1}$, Abiramavalli Kannamani²
}

${ }^{1}$ Senior Assistant Professor, Department of Obstetrics and Gynaecology, Thoothukudi Medical College.

¿2enior Assistant Professor, Department of Obstetrics and Gynaecology, Institute of Obstetrics and Gynaecology, Egmore, Chennai.

\section{ABSTRACT}

\section{BACKGROUND}

The objectives of this study are 1) To find out the incidence of premature rupture of membranes, 2) To evaluate the aetiology of premature rupture of membranes, 3) To assess foetal and maternal outcome in premature rupture of membranes.

\section{MATERIAL AND METHODS}

This prospective case control study was conducted in Govt. RSRM Lying In Hospital, Chennai, over a period of 6 months and 100 cases of spontaneous rupture of membranes attending the Department of Obstetrics and Gynaecology were studied. Maternal and neonatal outcome were compared with controls.

\section{RESULTS}

Incidence of PROM was 9.06\%. Most of them belonged to low socioeconomic class and in the age group 20-29 years, commonly seen primi gravida and in unbooked cases. Aetiological analysis revealed infection in $15 \%$ of cases, which is evident by positive amniotic fluid culture, h/o recent coitus in 20\%, mal-presentation in 7\%. Cause is unknown in most of the cases. The caesarean section rate is $24 \%$ when compared to $12 \%$ in control group. The PROM group had higher morbidities like postpartum haemorrhage, postpartum fever, wound infection, neonatal sepsis.

\section{CONCLUSION}

This study showed significantly increased morbidity for both mother and baby. PROM causes major increase in the incidence of prematurity, hence careful screening of high risk factors and treatment of infection promptly is needed to decrease the perinatal morbidity and mortality.

\section{KEYWORDS}

PROM, LSCS, Maternal Morbidity, Neonatal Morbidity.

HOW TO CITE THIS ARTICLE: Rodrigo MRR, Kannamani A. Perinatal and maternal outcome in premature rupture of membranes J. Evolution Med. Dent. Sci. 2016;5(51):3245-3247, DOI: 10.14260/jemds/2016/753

\section{INTRODUCTION}

Rupture of membranes before the onset of labour is defined as premature rupture of membranes. If it occurs before 37 weeks, it is called preterm PROM. If it occurs after 37 weeks, it is called as term PROM.[1] It complicates $5-10 \%$ of term pregnancies, about $30 \%$ of preterm deliveries. [2] $80 \%$ of PROM cases gets into labour spontaneously within 24 hours and the remaining within 72 hours.

In term PROM, if Bishop's score is favourable immediate stimulation policy is associated with good foetal and maternal outcome. If not, induction with prostaglandins is recommended.[3,4,5] Problems for the mother includes chorioamnionitis, postpartum fever, wound infection. Major problem for the baby includes infection, prematurity, nonreassuring foetal heart rate pattern due to cord compression.[6]

\section{MATERIALS AND METHODS}

For this prospective study, 100 cases of pregnant women with PROM is taken as study group and equal number of cases with no PROM and no complication are taken as controls.

Financial or Other, Competing Interest: None.

Submission 16-03-2016, Peer Review 13-04-2016,

Acceptance 20-04-2016, Published 24-06-2016.

Corresponding Author:

Dr. Mercy Rodrigo Rexy Rodrigo,

102-B, Kaliappar Street,

Thoothukudi-1.

E-mail: mercyravi2003@gmail.com

DOI: $10.14260 /$ jemds/2016/753

\section{Inclusion Criteria}

1. Singleton pregnancy between 28-42 weeks of gestation.

2. Primi and multi gravida.

3. Age group 18-40 years.

4. Leaking from cervix confirmed by speculum examination.

5. Cervix dilatation less than $3 \mathrm{cms}$.

6. No uterine contractions.

\section{Exclusion Criteria}

1. Multiple pregnancies.

2. Maternal complications interfering with active management of PROM like PIH, heart disease, previous LSCS.

Study group was further classified into term PROM and preterm PROM. All the patients were admitted in labour ward and started on 1 gm of Ampicillin every 6 hours and managed individually. Amniotic fluid culture and sensitivity was sent for all cases with PROM. Progress of labour was carefully monitored. Depending upon the maternal and foetal condition, labour was terminated by vaginal/instrumental/operative methods. For cases less than 34 weeks, corticosteroids were given. After delivery maternal and foetal outcome were studied. Foetal morbidity cases were admitted in NICU and subjected to investigations and followed till discharge. Mothers are also followed till discharge.

\section{RESULTS}

Incidence in Govt. RSRM Lying-in Hospital 9.06\%. 


\begin{tabular}{|c|c|c|}
\hline Age in Years & Study & Control \\
\hline$<20$ & 9 & 9 \\
\hline $20-29$ & 85 & 85 \\
\hline $30-40$ & 6 & 6 \\
\hline TOTAL & $\mathbf{1 0 0}$ & $\mathbf{1 0 0}$ \\
\hline \multicolumn{2}{|c|}{ Table 1: Age Incidence in PROM } \\
\hline
\end{tabular}

\begin{tabular}{|c|c|c|}
\hline \multirow{2}{*}{ PROM } & \multicolumn{2}{|c|}{ Latent Period } \\
\cline { 2 - 3 } & $<\mathbf{2 4}$ Hours & $>\mathbf{2 4}$ Hours \\
\hline Term & 77 & 3 \\
\hline Pre-Term & 13 & 7 \\
\hline \multicolumn{2}{|c|}{ Table 9: Relation of Latent Period and PROM } \\
\hline
\end{tabular}

\begin{tabular}{|c|c|c|}
\hline SE Class & Study & Control \\
\hline Low (IV \& V) & 98 & 97 \\
\hline Middle (III) & 2 & 3 \\
\hline Total & $\mathbf{1 0 0}$ & $\mathbf{1 0 0}$ \\
\hline Table 2: Socio-Economic Status in PROM \\
\hline
\end{tabular}

\begin{tabular}{|c|c|c|}
\hline An. Booking & Study & Control \\
\hline Booked & 38 & 60 \\
\hline Unbooked & 62 & 40 \\
\hline Total & $\mathbf{1 0 0}$ & $\mathbf{1 0 0}$ \\
\hline \multicolumn{2}{|c|}{ Table 3: Antenatal Care \& PROM } \\
\hline
\end{tabular}

$\mathrm{P}<0.001$ - significant

\begin{tabular}{|c|c|c|}
\hline Parity & Study & Control \\
\hline G1 & 67 & 68 \\
\hline G2 & 17 & 18 \\
\hline G3 & 13 & 11 \\
\hline G4 & 3 & 3 \\
\hline \multicolumn{2}{|c|}{ Table 4: Parity Incidence in PROM } \\
\hline
\end{tabular}

\begin{tabular}{|c|c|c|}
\hline Gestation in WKS & Study & Control \\
\hline$<34$ & 3 & - \\
\hline $34-36$ & 17 & 2 \\
\hline$>37$ & 80 & 98 \\
\hline Total & $\mathbf{1 0 0}$ & $\mathbf{1 0 0}$ \\
\hline \multicolumn{2}{|c|}{$\begin{array}{l}\text { Table 5: Incidence of PROM in } \\
\text { Relation to Gestational Age }\end{array}$} \\
\hline
\end{tabular}

\begin{tabular}{|c|c|}
\hline Cause & No. of Positive Cases \\
\hline Infection & 15 \\
\hline H/O coitus & 20 \\
\hline Mal-presentation & 7 \\
\hline H/O cervical surgery & 1 \\
\hline Not known & 57 \\
\hline Total & 100 \\
\hline \multicolumn{2}{|c|}{ Table 6: Aetiological Analysis in PROM } \\
\hline
\end{tabular}

\begin{tabular}{|c|c|c|}
\hline Organisms Grown & No. of Cases & $\%$ \\
\hline E. Coli & 6 & 40 \\
\hline Streptococci & 2 & 13.33 \\
\hline Klebsiella & 4 & 26.66 \\
\hline Proteus & 2 & 13.33 \\
\hline Pseudomonas Aeruginosa & 1 & 6.66 \\
\hline Total & 15 & 100 \\
\hline \multicolumn{3}{|c|}{$\begin{array}{c}\text { Table 7: Bacteriological Study of } \\
\text { Amniotic Fluid in PROM }\end{array}$} \\
\hline
\end{tabular}

\begin{tabular}{|c|c|c|}
\hline \multirow{2}{*}{ PROM } & \multicolumn{2}{|c|}{ Mode of Onset of Labour } \\
\cline { 2 - 3 } & Spontaneous & Induction \\
\hline Term & 26 & 54 \\
\hline Preterm & 14 & 6 \\
\hline \multicolumn{2}{|c|}{ Table 8: Mode of Onset of Labour and PROM } \\
\hline
\end{tabular}

\begin{tabular}{|c|c|c|c|}
\hline \multirow{2}{*}{ Mode of Delivery } & \multicolumn{2}{|c|}{ Study } & \multirow{2}{*}{ Control } \\
\cline { 2 - 4 } & Term & Pre-Term & \\
\hline Vaginal Delivery & 58 & 15 & 86 \\
\hline LSCS & 19 & 5 & 12 \\
\hline LMC & 2 & - & - \\
\hline Assisted Breech Delivery & 1 & - & 2 \\
\hline Total & $\mathbf{8 0}$ & $\mathbf{2 0}$ & $\mathbf{1 0 0}$ \\
\hline \multicolumn{2}{|l}{ Table 10: Mode of Delivery and PROM } \\
\hline
\end{tabular}

\begin{tabular}{|c|c|c|c|}
\hline Gestation & No. of Cases & LSCS & \% \\
\hline Pre-Term & 20 & 5 & $25 \%$ \\
\hline Term & 80 & 19 & $23.75 \%$ \\
\hline Table 11: Caesarean Section in Term PROM and PPROM \\
\hline
\end{tabular}

\begin{tabular}{|c|c|c|}
\hline WT. of Baby in KG & Study & Control \\
\hline$<2 \mathrm{KG}$ & 6 & - \\
\hline $2-2.5 \mathrm{KG}$ & 51 & 6 \\
\hline$>2.5 \mathrm{KG}$ & 43 & 94 \\
\hline Total & $\mathbf{1 0 0}$ & $\mathbf{1 0 0}$ \\
\hline Table 12: Baby Birth Weight in PROM \\
\hline
\end{tabular}

\begin{tabular}{|c|c|c|}
\hline 5' Apgar Score & Study & Control \\
\hline $2 / 10$ & 1 & - \\
\hline $6 / 10$ & 1 & - \\
\hline $7 / 10$ & 10 & 5 \\
\hline $8 / 10$ & 71 & 66 \\
\hline $9 / 10$ & 17 & 29 \\
\hline TOTAL & $\mathbf{1 0 0}$ & $\mathbf{1 0 0}$ \\
\hline \multicolumn{2}{|c|}{ Table 13: 5' Apgar Score in PROM } \\
\hline
\end{tabular}

\begin{tabular}{|c|c|c|}
\hline \multirow{2}{*}{ Morbidity } & \multicolumn{2}{|c|}{ No. of Cases } \\
\cline { 2 - 3 } & Term & Pre-Term \\
\hline PPH & 3 & \\
\hline Clinical Chorioamnionitis & - & - \\
\hline Postpartum Fever & 1 & 1 \\
\hline Wound Infection & 7 & \\
\hline Table 14: Maternal Morbidity in PROM \\
\hline
\end{tabular}

\begin{tabular}{|c|c|c|c|c|}
\hline \multirow{2}{*}{ Morbidity } & \multicolumn{2}{|c|}{ Preterm } & \multicolumn{2}{c|}{ Term } \\
\cline { 2 - 5 } & $\begin{array}{c}\text { No. of } \\
\text { Cases }\end{array}$ & $\%$ & $\begin{array}{c}\text { No. of } \\
\text { Cases }\end{array}$ & $\%$ \\
\hline Sepsis & 1 & 2.7 & 4 & 11.11 \\
\hline RDS & 6 & 16.66 & 4 & 11.11 \\
\hline Birth Asphyxia & - & & 4 & 11.11 \\
\hline Prematurity/SGA & 11 & 30.55 & 5 & 13.88 \\
\hline Meningitis & & & 1 & 2.7 \\
\hline \multicolumn{7}{|c|}{ Total Table 15: Perinatal Morbidity in } \\
\hline \multicolumn{6}{|c|}{ Term and Preterm PROM } \\
\hline
\end{tabular}




\begin{tabular}{|c|c|c|}
\hline Maturity & No. of Cases & \% \\
\hline Term & 1 & 1.25 \\
\hline Preterm & 2 & 10 \\
\hline \multicolumn{2}{|c|}{ Table 16: Perinatal Mortality in PROM } \\
\hline
\end{tabular}

\begin{tabular}{|c|c|c|}
\hline \multirow{2}{*}{ Causes } & \multicolumn{2}{|c|}{ Study } \\
\cline { 2 - 3 } & No. of Cases & \% \\
\hline Prematurity & 2 & $66.66 \%$ \\
\hline Birth Asphyxia/RDS & 1 & $33.33 \%$ \\
\hline \multicolumn{2}{|c|}{ Table 17: Causes of PN Mortality in PROM } \\
\hline
\end{tabular}

\section{DISCUSSION}

The incidence of PROM was $9.06 \%$ in this study, reported mainly in unbooked cases and women of low socioeconomic group. This is almost similar to the incidence of PROM in study conducted by Alberto Bacchi Madena et al (9-10\%). ${ }^{[7]}$ Arias (7$20 \%$ ).[8] Distribution of cases with regard to parity was not significant in this study (Table IV). The cause is idiopathic in most of the cases. Recent coitus, infection, mal-presentation were some of the risk factors identified in this study. This study also showed shorter the gestation longer will be the latency period and vice versa (Table IX).

In this study normal delivery is the commonest mode of delivery and the result is $76 \%$, which is similar to V. Kamala et al study. [9] LSCS rate in study group is $24 \%$, which is similar to Sita Ram Shreshta et al study.[10] LSCS was mainly done for mal-presentation and foetal distress. LSCS rate in preterm PROM is $25 \%$, which is higher than term PROM mainly due to cervical dystocia and foetal distress.

The most dreaded complication of PROM is chorioamnionitis.[11] But clinical evidence of infection is not seen in any of the cases due to intrapartum use of antibiotics. But $15 \%$ of patients in study group showed positivity in amniotic fluid culture (Table VI and VII). Only 2 patients had fever and 7 had wound infection. Among 3 cases of perinatal mortality, 2 babies died due to prematurity and its complications and one case due to birth asphyxia; 36 cases of perinatal morbidity was noted in study group, whereas only 4 cases had morbidities in control group. Even though PPROM is only $20 \%$ in this study, it contributes $50 \%$ to perinatal morbidity (Table XV).

\section{SUMMARY}

- Management of PROM lies between immediate stimulation of labour and expectant line of management.

- Immediate stimulation policy appears to be reasonable approach in multiparae and nulliparae with a good cervical score in term PROM.

- Expectant line of management is beneficial for preterm PROM patients, but signs of infection warrant broadspectrum antibiotics and prompt delivery.

- Abnormal labour and operative procedures have increased in PROM.

- This study showed careful antenatal monitoring for risk factors and aetiology detection and prompt treatment of infection and pelvic examination under aseptic precautions and appropriate antibiotics are important in prevention of PROM.

\section{CONCLUSION}

PROM is a high risk obstetric condition and it presents a great challenge to both obstetricians and paediatricians. Prompt diagnosis and effective management with careful selection of labour inducing agents are essential to deliver a healthy baby from a healthy mother.

\section{REFERENCES}

1. Onnig Tamizian, Arul kumaran S. Prelabour rupture of membranes. In: Arulkumaran S, Penna LK, Rao KB, editors. The management of labour Chennai: Orient longman publisher 2005; $2^{\text {nd }}$ ed:306-317.

2. Royal college of obstetrician-gynaecologists (RCOG), scientific advisory committee. Preterm prelabour rupture of membranes. Clinical green top guidelines No.44 London, UK: RCOG 2006;381391. Available at:http//www.rcog.org.uk/resources/public/pdf/green _top44_preterm.pdf.

3. Hidar S, Bibi $M$, Jerbi $M$, et al. Contribution of intra cervical PGE2 administration in PROM at term prospective randomized clinical trials. Journal Obs \& Gynaec Bioreproduction 2000;29(6):607-13.

4. Wagnar MV, Chin VP, Peters CJ, et al. A Comparison of early and delayed induction of labour with spontaneous rupture of membranes at term. Obstetrics and Gynaecology of India 1989;74(1):93-7.

5. Ozden S. Intravaginal misoprostol versus expectant management in prom with low Bishop's score at term. IJOG 2002;77(2):109-15.

6. Merowits NB, Anthony CV, Smulian JC, et al. Effect of labour on infant morbidity and mortality with prom: United States population- based study. Obstetrics and Gynaecology 2001;97(4):494-8.

7. Modena AB, Kaihura C, Fieni S. Pre labour rupture of membranes: recent evidence. Acta Biomed 2004;75(1):5-10.

8. Arias F, Daftary SN, Bhide AG. Premature rupture of membranes: in: practical guide to high risk pregnancy and delivery. Elsevier health sciences 2008;3rd ed.

9. Kamala Jeyaram V, Scaila Sudha. A study of premature rupture of membranes- management and outcome. Journal of Obstetrics and Gynaecology of India 2001;51(2):58-60.

10. Sita Ram Shrestha, Paban Sharma. Foetal outcome of prelabour rupture of membranes. N J Obstet Gynaecol 2006;1(2):19-24.

11. Amira El-Messidi, Alan Cameron. Diagnosis of premature rupture of membranes: inspiration from past and insights for future. JOGC 2010;32(6):561-69. 